\title{
Gendered Vocational Identities - Female Students' Strategies for Identity Formation During Workplace-Based Learning in Male-Dominated Work
}

\author{
Lisa Ferm, Maria Gustavsson \\ Department of Behavioral Sciences and Learning and HELIX Competence Centre, \\ Linköping University, 58183 Linköping, Sweden
}

Received: 01 February 2021, Accepted: 08 November 2021

\begin{abstract}
Purpose: This article investigates female vocational students' strategies for becoming part of a workplace community, what these strategies are and how they are tied to the formation of vocational identities within male-dominated industrial work. Of particular interest is how female students enrolled on Swedish upper secondary industrial programmes experience workplace-based learning at industrial workplaces as part of their vocational education. The theoretical framework derives from Wenger's concept of community of practice, but his theoretical concept does not explicitly include gender dimensions. Therefore, the concept of community of practice is also combined with Paechter's assumption of gender, whereby femininity and masculinity can be considered as different communities of practice.

Methods: The article draws on evidence from a Swedish study based on interviews with 20 female students enrolled on the industrial programme at six upper secondary schools. In this vocational programme, there is a distinct gender distribution and only a small minority of the students on the programme are girls. In the analysis, the focus is on the female students' strategies used during workplace-based learning to become part of the work community which consists almost exclusively of male workers.
\end{abstract}

*Corresponding author: lisa.ferm@liu.se 
Findings: The female students deliberately negotiated vocational identities as female industrial workers to become accepted in the male-dominated work community. The findings highlight three specific strategies that the female students used: Acting like gender does not matter, acting like boys (not like drama queens), and acting tough and joking around. The female students' strategies were part of - and tied to - a complex vocational identity formation process that featured contradictory requirements. By taking individual responsibility, they identified relevant information for becoming industrial workers and chose to act like boys. The female students saw no problem with being a girl, yet they struggled with implicit, diffuse and hidden gender structures and prejudices in the male-dominated industrial companies. Nevertheless, they strived for what they perceived to be an attractive vocational identity as industrial workers; it was an alternative, atypically feminine way of being that attracted the female students.

Conclusions: The study concludes that female students mostly rely on their individual agency when interacting with others in the male-dominated workplace community. A "gendered vocational identity" is formed which shows that the identity formation of female students is a complex double process, in which vocational and gender identities are formed simultaneously and in parallel within the male-dominated workplace.

Keywords: VET, Vocational Education and Training, Vocational Identity Formation, Gender, Student, Workplace-Based Learning

\section{Introduction}

This paper focuses on female vocational students' strategies for forming a vocational identity as industrial workers in the male-dominated industrial sector. Of particular interest is how female students enrolled on the Swedish upper secondary industrial programme experience workplace-based learning at industrial workplaces as part of their vocational education. Workplace-based learning has been found to have a great significance for vocational students' vocational identity formation (Helms Jørgensen, 2013; Klotz et al., 2014). As Klotz et al. (2014, p.17) suggest, students "cannot form worthwhile, robust vocational identities without experiencing work and without actively engaging and learning in workplaces". A close relationship between students' workplace-based learning and their access to the work community in industrial companies seems paramount for the potential strategies students use to learn their chosen vocation and develop a vocational identity (Evans et al., 2010; Ferm et al., 2018). Therefore, a vocational identity can be seen as a determination for becoming a member of a vocational community (Armishaw, 2007), which implies actively engaging in the workplace. With regard to the female students' minority position on the industrial programme and during their workplace-based learning at companies, their gender position 
can have a significant impact on the formation of a vocational identity as industrial workers (Ledman et al., 2020; Paola Sevilla et al., 2019).

The Swedish upper secondary industrial programme features a distinct gender distribution. Only a small minority of the vocational students on the programme are girls. In the academic year 2019/2020, 10.8 per cent were female. The number of female students has, however, increased slightly since 2011 when the programme was launched in its current form, but was at its highest (11.6 per cent) in 2016 (Swedish National Agency for Education, 2020). Attempts made by feminists, researchers and unionists to highlight the issue of gender segregation in male-dominated vocational programmes and to illuminate the social and economic advantages of a higher percentage of female students have not yet had any significant impact on the number of female students on such programmes (Struthers \& Strachan, 2019). There is growing interest in examining the implications of gender in vocational education (Lappalainen et al., 2012; Tanggaard, 2006), and more specifically the experiences of female students in male-dominated vocational education (Paola Sevilla et al., 2019). However, studies of gender issues in different vocational education have had a primary focus on boys rather than girls in gender-segregated education (Ledman et al., 2020). Few studies (if any) have focused on female vocational students on the industrial programme and their preparation through workplace-based learning to enter a male vocational domain such as industrial manufacturing companies. Vocational education that relies largely on students' workplace-based learning such as the industrial programme also reflects the overall gender order found within the industrial sector and the labour market (Pleasant, 2019). Therefore, it is also important to consider gender issues in general when studying vocational education, because the vocation in itself can be gendered which affects the conditions for entering a specific vocation.

The knowledge gap presented above regarding female students' vocational identity formation, together with the strong gender segregation in industrial work and education, constitutes the background for this study. The aim of this article is thus to investigate female vocational students' strategies for becoming part of a workplace community, what these strategies are and how they are tied to the formation of vocational identities within male-dominated industrial work.

The female students who are the focus of this study will be referred to as girls in order to reduce the number of repetitions. The paper draws on evidence from a Swedish study based on interviews with 20 girls enrolled on the industrial programme at six upper secondary schools. In the analysis, the focus is on the girls' strategies for becoming part of the work community which consists almost exclusively of male workers in industrial companies. In the discussion, we argue that girls on the male-dominated industrial programme negotiate vocational identities as female industrial workers in a deliberate way during the workplacebased learning by using different strategies to become accepted as an industrial worker in the workplace. 


\section{Previous Research}

This section presents previous research on barriers faced by girls on male-dominated vocational programmes, gender stereotypical expectations, and gendered discourses in vocational education and work.

\subsection{Barriers for Girls in Male-Dominated Vocational Programmes}

There are a few studies that focus on the challenges and barriers girls encounter due to gender in male-dominated vocational programmes. Paola Sevilla and colleagues (2019) have found that girls in male-dominated vocational education were exposed to benevolent sexism in the form of praise and protecting girls from hard work. Despite good intentions, this type of sexism operates as a barrier by influencing the work tasks girls are offered and making it difficult for girls to access learning opportunities and be accepted at workplaces (Paola Sevilla et al., 2019). For vocational female students subjected to sexist treatment at male-dominated workplaces, Tanggaard (2006) identified that their strategy was to participate in the male discourse by answering back and treating the men in the same way as they were treated. These female students actively refused to accept the role of an oppressed and intimidated girl (Tanggaard, 2006). A similar strategy was identified by Ely (1995) among women in maledominated work, who dealt with sexist treatment by acting more like men and less in accordance with traditional femininity. Other studies have found that girls in male-dominated vocational programmes are viewed as weak and are therefore excluded or questioned when it comes to carrying out physically demanding work (Tanggaard, 2006; Åberg \& Hedlin, 2015). Girls who chose to work in automotive engineering were seen as entering an overly dangerous and demanding job, while at the same time they were liked just for being feminine (Ledman et al., 2020). Korp (2011) discerned difficulties for girls on the male-dominated transport programme in terms of being feminine, because this was seen as something odd that boys made fun of.

Other studies have identified barriers related to vocational teachers' negative judgements of girls' unsuitable characteristics in relation to male-dominated vocational education. Lappalainen et al. (2012) found that female vocational teachers reproduced the stereotype that there is a lot of gossip and drama in situations where women are in the majority. These teachers viewed girls as more precise and prepared than boys, which they saw as characteristics that prevented girls from mapping important aspects of work in the same way boys did (Lappalainen et al., 2012). Kontio and Evaldsson (2015) discovered that vocational teachers on the vehicle engineering programme predicted that the few girls enrolled would drop out within a year, as they risked being marginalised due to the masculine norms that pervade the education. Girls who do not choose typically male vocations make a rational decision to 
avoid the risk of discrimination and harassment (Colley, 2006), while girls in typically maledominated vocational education seem to expect to have a harder time being accepted in the workplace than boys (Paola Sevilla et al., 2019).

\subsection{Gender Stereotypical Expectations}

Gender stereotypical expectations refer to the types of vocations that are deemed suitable (or unsuitable) for women and how women in traditional male-dominated vocational education and workplaces should behave and act, for example in construction and engineering (Struthers \& Strachan, 2019). As Joan Acker's (2006) seminal research has shown, gender expectations are shaped in relation to the existing explicit and implicit gendered norms of a particular profession. Struthers and Strachan's (2019) investigation of secondary school girls' perceptions of the male-dominated automotive engineering and construction industries shows that they were exposed to gender expectations, suggesting that such vocations were options for boys who did not fit into academia. These types of expectations led to doubts about choosing education for a typically male vocation. These girls did not receive sufficient information about male-dominated programmes and vocations before applying for upper secondary school. The low status of male vocational education compared to academia was a factor the girls contemplated because they could make alternative educational choices in which they did not risk being intimidated due to their gender. These girls also were worried about adopting the identity of a male vocation which was not compatible with their feminine identity, and that they felt a fear of being stereotyping as unfeminine.

By contrast, Paola Sevilla et al. (2019) found that girls' choices of technical vocational education depended on their intention to do something that was regarded as atypically female. Further, Paola Sevilla and colleagues imply that the girls opposed what society considers to be typically feminine attributes by entering a traditionally male-dominated industrial specialisation. Resistance to a feminine identity was also a feature found among the girls studied by Ledman et al. (2020). By resisting femininity, the girls moved their position closer to the selected male vocational identity. Masculine attributes such as competition and direct confrontation permeate vocational identities on traditionally male vocational programmes (Tanggaard, 2006). Others' expectations of female students shape the way they adapt to masculine actions, and also when they had to provide a 'woman's touch' (Paola Sevilla et al., 2019) by applying certain qualities that boys lack, for example being careful, thorough (Ledman et al., 2020; Paola Sevilla et al., 2019). Such characteristics are also used as explanations why employers in male-dominated industries want to hire more female workers (Ledman et al., 2020).

Another gender expectation found by Korp (2011) was that girls on the male-dominated transport programme were supposed to handle the male banter. The female students who could handle the male humour were highly valued. Participating in the male banter 
was something that the girls saw as an opportunity to present themselves as smart workers. Sometimes these girls had to act like men to be able to fit in on the male-dominated programme (Korp, 2011). Kontio and Evaldsson (2015) affirmed the same pattern on the vehicle engineering programme, where the girls were expected to participate in the male banter by receiving and making comments in the same way as the boys did on the programme.

\subsection{Gendered Discourses in Vocational Education and Work}

In previous research, two significant discourses appear - an individualistic discourse and a genderless discourse - in relation to vocational education and male-dominated vocations. The individualistic discourse focuses on self-conceptions. In relation to gender, self-conceptions can foster an uncritical acceptance of faults that one attributes to oneself, for example as a woman in comparison to men, to justify one's own 'negative' attitudes and shortcomings (Wetherell et al., 1987). In a study of girls, Colley (2006) discovered that they tended to believe that equal opportunities existed regardless of gender in working life and in choosing a vocation. At the same time, these girls were exposed to gender discrimination such as stereotyping and harassment in the workplace. As a consequence, they often blamed themselves, as they thought that the derogatory treatment had something to do with them as individuals rather than being related to gender inequalities and the contemporary societal structure. Gustavsson and Fogelberg Eriksson (2010) found that gender inequalities in a male-dominated manufacturing company were attributed to individuals' shortcomings, which reinforced the individualistic discourse and neutralised gender differences by stressing that everyone has the same chance for advancement within the company. Similar findings were noted by Korvajärvi (2002), who investigated clerical workers at an IT call centre and in a social work office. These clerical workers regarded gender as a private part of their individuality and as irrelevant to their work or anything that affected their opportunities to advance at work. Nevertheless, the gender structures created inequalities on a structural level, and gender issues were treated as irrelevant for work which was a part of the workplace culture (Korvajärvi, 2002).

Depicting gender as irrelevant is closely related to the discourse of 'genderless gender'. This discourse makes gender appear less important and suppresses the effects of gender by talking about both men and women as merely "individuals" in order to downplay issues of gender. In other words, gender does not matter (Lahelma, 2011; Lappalainen, 2012). The notion of genderless gender appears in Lappalainen et al.'s (2012) analysis of vocational teachers' reflections on gender-related in the male-dominated technology and transport programme. These teachers adopted a discourse of gender neutrality grounded in their professional code and dismissed the importance of gender in their dealings with students and colleagues. By contrast, the female vocational teachers had to deal with masculine vocational hierarchies in 
order to be respected as vocational teachers (Lappalainen et al., 2012). Gender neutrality can be expressed through objective and professional ideals such as muting the role that gender plays in work-related relationships and instead adopting a discourse that gender does not matter (Risberg, 2004). Advocating inclusiveness in vocational education can also signify that gender does not matter. Paola Sevilla et al. (2019) refer to "apparently inclusive discourses that, by reducing the importance of the student's gender, obscure existing obstacles for female students to enter the industrial area" (Paola Sevilla et al., 2019, p. 14). This implies that there can be gendered structures in the shadow of equal conditions for individuals, creating unequal conditions for female and male students.

\section{Theoretical Framework}

The concept of communities of practice is selected as a theoretical foundation for analysing female vocational students' strategies for becoming part of a workplace community, what these strategies are and how they are tied to the formation of gendered vocational identities in male-dominated industrial work. Being a member of a community of practice implies a commitment to participating and engaging in a joint activity within a specific area or domain which defines the community's identity (Wenger, 2010). In this case, the community's identity is tied to male-dominated industrial work. A community of practice provides a foundation for learning and collaboration, creating relationships and mutual trust among its members (Wenger, 1998). Each community of practice develops its own repertoire of tools, methods, routines and work activities by sharing knowledge and experiences (Wenger, 1998). When entering a particular community of practice, apprentices (students) are legitimate peripheral participants and, with experience, they become full participants who gradually develop identities (Lave \& Wenger, 1991). An apprentice must be able and allowed to engage actively with experienced workers and gain access to the joint repertoire used in the community of practice. However, as Fuller and Unwin (2003) argue, apprentices' participation in a community of practice varies depending on whether they have access to a range of vocational qualifications and whether formal arrangements are designed to support the apprentices' participation and identity development.

Engaging with others entails active negotiation of ways of being and strategies for meeting and dealing with the requirements of the community. As Wenger (2010) argues, in the process of negotiation every community of practice invites the apprentices into a new identity that fosters certain ways of being and performing in the practice of the community. Evans et al. (2010) suggest that vocational students who alternate between school and workplaces form strategies when integrating what they have learned at school with experiences from collaborating with skilled workers during workplace-based learning. Strategies are not always well thought out and rational. In fact, students can be unaware of the strategies used in work 
until they look back at their experiences in hindsight (Evans et al., 2010). As we have shown elsewhere (Ferm et al., 2018), students' vocational identities are developed in response to different strategies of learning, such as taking individual responsibility, asking questions and finding role models to become a member in a community of practice.

While we recognise the relevance of the community of practice approach for analysing the female vocational students' strategies for becoming part of a male-dominated community and vocational identity formation, we identify shortcomings in this theoretical approach because it does not explicitly incorporate gender dimensions. In this regard, inspired by Paechter's (2003) approach to communities of practice, we move to the idea that femininity and masculinity can be regarded as different communities of practice. Looking at femininity and masculinity as communities of practice means that the focus is on how gender is done by participating in everyday situations (Paechter, 2003; West \& Zimmerman, 1987). This signifies that gender is connected to participation and, as Wenger (2010, p.141) puts it, "women who seek equal opportunity often find that the practices of certain communities never cease to push them back into identities of non-participation". According to Wenger (2010), non-participation is just as relevant as participation. He adds that non-participation does not necessarily develop an identity as an outsider who is marginalised. However, it is not always up to individuals to choose freely which communities of practice to participate in. Certain communities may be reluctant or refuse to include certain people for various reasons.

Paechter (2003) argues that women and men form femininities and masculinities differently within a community of practice. Therefore, femininity and masculinity are associated with local ways of dealing with norms and ideals in a community of practice, and this is an important part of individuals' identity formation (Paechter, 2003; Tanggaard, 2006). What is expected of male and female members is constantly under negotiation, and they are not fixed roles (Paechter, 2006a). Within different communities of practice, the meaning of being a woman or a man is constantly negotiated and reproduced (Paechter, 2003). This means that gender is continually done by individuals in different communities (Paechter, 2003; West \& Zimmerman, 1987).

Nevertheless, both women and men as individuals may do gender differently, depending on which community they find themselves in, and new members learn what it means to be a woman or man when entering the community. This learning process forms a shared practice of trying to live up to norms and ideals of being a woman or a man in a specific community of practice. This shared practice may also lead to the formation of localised masculine and feminine identities (Paechter, 2003). However, when individuals do gender, they do not always live up to traditional expectations of femininity or masculinity. Even when they do gender in untraditional ways, their behaviour is still interpreted based on their gender (West \& Zimmerman, 1987). For example, not aligning to the ideals of what it means to be a woman or a man in an established community of practice may lead to exclusion from the community (Paechter, 2003). 
A community of practice can be maintained as long as there are forces of power that pervade formal and informal gender structures. In this sense, belonging to a community of practice means that one must identify with its recognisable power dynamics to form an identity (Wenger-Trayner \& Wenger-Trayner, 2015). As Paechter (2006a) emphasises, power and gender are closely connected and influence how communities of practice will function, the degree of power they will have and who will be granted access to participation. Membership will only be provided to those who fully grasp what it means to be a woman or a man in that specific community, which involves being and behaving in ways that are accepted by the community (Paechter, 2006a). Power and knowledge are always connected, and different types of knowledge are coded as masculine or feminine, but are also ascribed different statuses in different communities of practice (Paechter, 2003). One way to claim power is to disconnect oneself from femininity, and this distancing may include disidentification with women and identification with men (Paechter, 2006b).

\section{$4 \quad$ Research Context}

The study was conducted at six Swedish upper secondary schools offering the industrial programme. The industrial programme is male-dominated, and currently just under 11 per cent of the students are female. In Sweden, each upper secondary programme lasts for three years and the students enrolled are between 16 and 19 years old. Of the 18 programmes offered within the Swedish upper secondary school system, six are higher preparatory programmes and twelve are vocational programmes. The upper secondary vocational programmes are offered as two different models, a school-based model and an apprenticeship model. The school-based model must provide a minimum of 15 weeks of workplace-based learning, while in the apprenticeship model 50 per cent of the entire education must comprise workplace-based learning. Formally, the time students spend on workplace-based learning is different in the two models, but in practice this difference is not significant. Regardless of the model, each school has considerable scope for manoeuvre to determine the length of students' workplace-based learning. In other respects, there are no major differences. Both models' main curriculum goals are to provide familiarisation with industrial work and the role of an industrial worker. Both models lead to the same type of qualification.

\section{Method}

The study is based on a qualitative research approach, and includes 19 interviews with 20 girls enrolled on the industrial programme at six different upper secondary schools.

The research that is carried out in this study has been approved by the Regional Ethics Board in Linköping (ref. 2014/438-31). 


\subsection{Selection of Participants}

The selection of girls was conducted in two steps. In the first step, carried out in 2015, eleven girls were selected for the larger research project. At this stage of the project, both girls and boys were selected since being a female student in the male-dominated industrial sector was not an exclusive focus. The overall focus was on students' vocational learning and identity formation as industrial workers. During these first interviews with the eleven female students, they described their experiences and feelings in relation to being a girl on a male-dominated vocational programme and in male-dominated workplaces. In the second selection step in 2019, nine additional girls were selected.

In both selection steps, the girls were contacted through the principals responsible for the industrial programmes at the six schools. The principals were provided with written information by email about the research study. After the principals had given their informed consent, they informed the students. Girls who voluntarily decided to participate in the study were contacted at the school by the researchers.

The interviewed girls were between 18 and 20 years old. Five of the girls were enrolled in the apprenticeship model of the industrial programme, while the remaining 15 were studying the school-based model. Fifteen girls were in their third and final year of the programme, and five girls were studying their second year. All 20 girls had experience of workplace-based learning within process industries and manufacturing companies of varying sizes, from a few employees to multinational industrial companies with several hundred employees. The most common vocational orientation amongst the girls interviewed (eight girls) was welding, although other orientations were also represented such as operations and maintenance or production and machine technologies.

\subsection{Data Collection}

All interviews took place at the schools and were conducted individually with the girls, with one exception of two girls who wished to be interviewed together. The first interview round was carried out by the two authors and a research colleague in the research project, and the second round by the first author of this article. The interviews ranged from 24 minutes to 85 minutes but lasted approximately an hour. The interviews were semi-structured with guidance from an interview guide. The first round of interviews covered questions about workplace-based learning, ways and conditions for learning a vocation and an identity as an industrial worker. In the second interview round, the same interview questions as in the first round were used, but additional questions that explicitly focused on gender were added, for example: "What are your experiences of being a student in a male-dominated workplace?" and "How do you experience the way that boys and girls are treated in the workplace where you conduct your workplace-based learning?" 
The girls talked openly about their experiences, thoughts and feelings about the subjects, and the researchers followed up by clarifying or providing supplementary questions to expand the answers. All the interviews were recorded and transcribed.

\subsection{Data Analysis}

The analysis was carried out inductively in a sequence of steps inspired by Braun and Clarke's (2006) qualitative thematic analysis. In the first step, all interviews were read repeatedly, in order to become familiar with the material (Braun \& Clarke, 2006). In the next step, extracts where the girls mentioned experiences or thoughts that explicitly related to them being female or the gender division in the industrial sector were collected in a separate document for further analysis. This document contained extracts from both the first and second rounds of analysis and was interpreted as comprehensive material containing coherent empirical data. The extracts were read several times and notes were taken during the analysis process, focusing on parts of the interviews where the girls actualised gender issues on their own and where the researchers introduced the subject of gender.

In the extracts, eight recurrent categories were identified: Advantages of being a girl, disadvantages of being a girl, gender does not matter, preferring the company of boys, the attitude of a female industrial worker, being treated as fragile, the importance of other girls, and plans for the future. These categories were then further analysed. During this part of the analysis process, it became evident that the categories shown that the girls had a high degree of individual agency in the process of forming a vocational identity. This discovery led to a further analysis step in which the categories were reduced into three strategies that illustrate how the girls' individual agency created ways to act in the workplaces to become a part of the work community and form a vocational identity as industrial workers. These strategies are presented in the findings section below.

In the presentation, the female students from the first round of interviews have been given names beginning with A while the girls interviewed in the second round have been given names starting with $\mathrm{B}$.

\section{Findings}

The findings demonstrate three strategies that the female vocational students used during their workplace-based learning for becoming part of a workplace community that consisted almost exclusively of male workers. Using these strategies, the girls negotiated their gendered vocational identities to be accepted as industrial workers in male-dominated companies. 


\subsection{Acting Like Gender Does not Matter}

One important strategy used by the girls was to downplay gender issues by talking about how gender does not matter. The girls approached gender issues by pointing out that gender did not create any problems; gender was thus viewed as a non-issue. The gender expectations the girls placed on themselves were to repeatedly act in ways which showed that gender did not matter, for example by answering that it made no difference to their workplacebased learning and that the gender division of the industrial education and vocation did not matter much to them. The girls said that they did not think of gender because it was not a relevant issue for learning the work as an industrial worker or gaining access to working life experience. Instead, it was important for the girls to employ a strategy that focused on expressing a neutral identity as an industrial worker rather than focusing on themselves as belonging to an underrepresented gender.

Bella: I don't usually think about things like why there aren't that many girls here, you know, I mostly think about what I'm about to do, my work. It doesn't matter that much to me.

The girls' focus was on the work and on alignment to the workplace culture, rather than on gender issues related to the vocation. Many female students perceived that they were treated in the same way as the boys who were vocational students at the workplaces. The girls saw no difference between them and the boys in terms of how they were instructed by the workers or when it came to receiving help when needed. The girls often emphasised that they were not excluded due to their gender.

Britta: Everyone is very nice over there (at the workplace), it's not like you are excluded just because you are new or a girl or anything like that, we usually play cards or just sit and chat. Bea: They treat me very well, it makes no difference to them whether I'm a girl or a boy, they believe in me regardless. It's nothing special at all.

Later in the interviews, despite the fact that the girls often used the strategy of acting like gender does not matter in order to gain acceptance in the workplace community, it was apparent that they were sometimes treated differently due to their gender. This treatment could be both positive and negative, bring both advantages and disadvantages when entering the male-dominated workplaces. Some examples of advantages that the girls mentioned were that they were seen as attractive employees by companies that strived for a more even gender distribution. They were also considered to possess qualities that boys lacked, such as being thorough and precise when performing certain tasks. Examples of disadvantages the girls described were that they were seen as too fragile for industrial work or as outsiders who did not have a natural place in the company. 
In the interview below, two girls who had experienced being treated negatively due to their gender discuss the question of what it is like being in a male-dominated workplace.

Bea: Well, I actually don't care that much.

Becky: No, me neither. I was raised with men.

Bea: Yes. I'm there to work, I don't care if... = if there is ((laughing))

Becky: ... if there aren't any girls.

Bea: I can kind of work with anyone.

Becky: It's like, nothing special.

The two girls found explanations that reinforced that gender did not matter, such as that they did not care and they could work with anyone even though they could be treated differently in a negative way. The strategy of acting like gender does not matter was a way to convince themselves and others that gender was not a problem. Aligning with the work community implied not focusing a lot on gender issues, but rather adopting the traditionally masculine culture of the workplaces. The gender neutrality façade was a beneficial way to gain acceptance, but in some situations the girls felt that they were treated differently due to their gender.

\subsection{Acting Like Boys - Not Like Drama Queens}

Another strategy that the girls used to fit into the male-dominant community was to adopt masculine behaviours and to distance themselves from the negative image of girls as drama queens. For example, they actively engaged in establishing masculinity, such as participating in the industrial jargon, making fun of the other workers and coping with being joked with, getting their hands dirty and working with heavy tasks. Some girls felt more natural and comfortable in the company of boys than with other girls.

Belinda: I didn't play a lot with dolls or Barbies or things that are thought of as girly, I was more out playing in the sandbox and with cars. I played a lot with my big brother when I was little. So, I guess it's been a part of my upbringing, that I haven't played that much with girly things, so for me it's completely natural that... I think it's nice that there are only boys.

Adopting traditionally masculine ways of acting allowed the girls to distance themselves from the "drama" that they perceived other girls often created in social situations, such as talking behind each other's backs or being easily offended by banter. Some girls felt that boys did not engage in such activities to the same extent as girls, which is why the female students often tended to prefer the company of boys.

Anna: It is mostly nice because there are just lads in the class... there are no girl dramas. I guess there have been some, but none that I have participated in. 
One way for the female students to distance themselves from traditional femininity was to act like relaxed workers who did not participate in drama. Being relaxed also involved dissociating themselves from a 'feminine sensitivity', a way of acting among women that was often considered to results in insults and conflicts.

Bella: My sense of humour is more like that of a boy.

Researcher: What does that mean?

Bella: Well, some different things I suppose. It's kind of like... most boys don't care that much about what they say and who might feel offended by it. But with girls, if you say something wrong, most of them are like 'You can't say that, what if he feels offended or what if she feels like that'. I think that is kind of hard.

The girls were often attracted by industrial work because they wanted to do something that was not typically feminine. Therefore, they saw male-dominated industrial work as an alternative way to change their identity and not be seen as a 'little girl' anymore, as one of the girls put it. One girl explained that she "wanted to do something that not all other girls do". Another girl expressed that she found enjoyment and satisfaction in being the only girl on the shop floor among the male workers.

Agnes: I didn't mind it at all, being the only girl on the floor. It didn't bother me at all, it was almost just fun to get to feel what it was like to be alone. To not be able to go to somebody and cry about how someone was mean to me, because you don't exactly do that to a boy if you are a girl.

As the quotation illustrates, feeling enjoyment at being the only girl in the work community also indicates that it was not necessary to have female workmates. Despite being biased in their actions towards masculine gender forms, the girls did not necessarily disengage from other girls. Later in the interviews, some girls suggested that in order to attract more girls to enrol on the industrial programme there could be female ambassadors to rectify the low number of girls in industrial work. On the other hand, the girls explained that other girls could have a bad impression of industrial work as being heavy and dirty, which was considered an incorrect perception as industrial work had changed. Due to the misleading image of industrial work, their opinion was that more girls would be encouraged to apply to the industrial programme and work at companies if they had the opportunity to experience what it really was like.

\subsection{Acting Tough and Joking Around}

The third strategy that the girls used was to adopt an attitude of acting tough and joking around, to fit into the male-dominated work community and to deal with the resistance they sometimes encountered in workplaces due to their gender. For example, several girls described experiences of being seen as more fragile than boys in situations where they were 
faced with heavy lifting or being subjected to masculine banter. As a consequence of this female attribution, they felt that their capacity to execute the work was questioned, as was their ability to deal with the banter in the work community. Part of the strategy was not to take things personally or be offended and to ignore the male workers' negative perceptions about female workers in general. Instead, the girls expressed that a useful way of dealing with the men's jokes was to show that they appreciated the banter.

Anna: You have to show that you think their jokes are funny and that it's OK to joke with me, and that you're not shy but can handle most things. [...] It's a lot of, well it can be everything from racist jokes to sex jokes, so you have to take it with a pinch of salt.

If one part of the strategy of acting tough and joking around was to not care in a passive way or give any thought to unfair treatment due to negative stereotypes about women, another part was to participate actively in the banter and make jokes in the same way that the men did. The girls said it was important to show that they could deal with banter in accordance with workplace norms and expectations. Being able to handle banter from male workers meant receiving comments without showing feelings of being insulted or becoming emotional, as well as giving quick replies and making jokes back to the men. A common way to deal with the banter was to treat the men in the same way that the men treated the girls.

Belinda: I handle the banter like, well I treat them like they treat me. If they make a comment, I make a comment that's much worse and then you kind of start to laugh about it.

Encountering banter from male workers was something the girls were used to, and something that they had to learn in order to access tasks in the workplace. An important attribute for the girls to endure the pressure was to be strong in order to profile themselves as capable workers.

Amanda: There's a lot of special treatment, like: 'Can you really handle that, are you strong enough?' And you don't get to prove it so you're just like 'Well yes, I can take care of myself'. But you just have to tell them off and then you get to take on the job yourself anyway.

Standing up for oneself was a way of acting tough, and sometimes it also included developing their own solution that served as a tool for breaking through the reluctant male culture. One girl described her longstanding efforts to gain acceptance from male workers as follows.

Alice: It was mostly guys between 30 and 35 , maybe up to 40 , that had problems, but they didn't do anything, they just glowered and walked past me, didn't say hello. But that wasn't a problem, I don't take it personally.

Researcher: But you said that you finally got the guys to say hello. How did you do that? Alice: I don't know, I always walked around and tried to smile a lot, simply trying to make them say hello, make them laugh a little, kind of letting go of that stiff feeling. So finally, it worked. 
This girl also described that it required a great social effort on her part to get the male workers to simply greet her in the morning. Despite being ignored by the men, she continued to smile and show a happy face when meeting them. Eventually, she persuaded the men to greet her by using her gently humorous manner. It was important for the girls to be able to demonstrate that they could handle jokes and banter, to win appreciation and to be seen as a colleague in the work community.

\section{Discussion}

The findings of this article provide an insight into female vocational students' strategies for becoming part of a workplace community within male-dominated industrial work. As our findings suggest, the female students' agentic attitudes and actions created strategies to gain access to the workplace community and to position themselves as industrial workers. The findings highlight three specific strategies that the girls used: Acting like gender does not matter, acting like boys (not like drama queens), and acting tough and joking around. These strategies served as a basis for creating relationships and achieving acceptance that gave the girls access to the male-dominated community of practice (Paechter, 2003). The female students' active engagement in the male-dominated community implied a commitment to participate in a joint work activity (Wenger, 2010) to achieve a vocational identity for work in industrial vocations that they often found very attractive. Although the girls approached what they perceived as an attractive vocational identity, the strategies can also be understood as a response to distance themselves from traditional femininity in their bid to compensate for negative gender prejudice and seek equal opportunities as men (Wenger, 2010).

The strategy of acting like gender does not matter seemed to be a way to maintain gender neutrality as part of the formation of a vocational identity, despite the fact that the girls were treated differently. By not paying attention to gender issues or how structures and hierarchies of gender could affect them, they saw themselves as solely responsible for being accepted in the workplace community. The girls' self-responsibility and neutralisation of gender to become part of the masculine workplace community seems to be in line with an individualistic and genderless discourse found in previous research (Colley, 2006; Gustavsson \& Fogelberg Eriksson, 2010; Lahemla, 2011). It was up to the girls to prove that they were suitable for the vocation. Therefore, the girls' own explanations repeatedly drifted towards gender not mattering in relation to the vocation, in order to gain access to tasks and guidance from experienced workers and to fit into the community of male workers. The girls downplayed gender issues and effects by saying: "Everybody is nice and treats me well", and "I am not excluded because I am a girl" (cf. Lahelma, 2011; Lappalainen, 2012). Nevertheless, ambiguities were found in the girls' interview responses. They also talked about being exposed to unequal treatment that led to both advantages and disadvantages of being a girl in the 
male-dominated workplace. One explanation for the ambiguity between showing a strategic attitude to fit in and their experiences of actual treatment may be that conversations about gender were not an accepted issue of the male-dominated working culture (Korvajärvi, 2002; Risberg, 2004); a masculine community of practice (Paechter, 2003) in which the girls actively tried to become full participants and form a vocational identity (Lave \& Wenger, 1991; Wenger, 2010) as industrial workers. The strategy of acting like gender does not matter seems to contradict the other two strategies, which focus on behaving like men in order to become accepted in the community of practice, but all three strategies seem to operate in parallel. The difference is that the strategy of acting like gender does not matter is about not engaging in gender issues but perceiving oneself as a worker rather than a girl, and thus adopting the discourse of genderless gender (Lahelma, 2011; Lappalainen, 2012). On the one hand, this implies that the girls' gender is irrelevant to the work. On the other hand, it contradicts their experiences of being treated differently to male workers.

It has been shown that masculine attitudes may force female students in male-dominated vocations to behave like boys (Ely, 1995; Korp, 2011). In contrast to previous research, the girls in this study often felt comfortable with the masculine attitudes in the workplace community. Choosing to act like boys and not like drama queens was the female students' second strategy, suggesting that they appreciated the masculine environment. A drama queen was an image or identity attributed to other girls, not to girls who participated in the industrial programme. Expressing not being a drama queen served as a way to disconnect oneself from the traditionally feminine way of being (Paechter, 2006b) and doing something that was seen as atypically female (Paola Sevilla et al., 2019). The girls actively positioned themselves as girls who preferred to work in the industrial sector, getting dirty and not complaining about arduous tasks. Working in such circumstances and together with men made them feel freer and more relaxed than in female contexts. The girls were often proud and found freedom in their future vocational identity. It can therefore be said that they also moved their position closer to becoming an industrial worker (cf. Ledman et al., 2020).

Industrial work was valued by the girls as an attractive job. It therefore also became important to the girls to prove that they could tolerate jokes from male workers and cope with the pressure of acting tough in order to break through the male-dominated workplace culture. This type of strategy was apparent in some of the female students' concrete suggestions for finding their own solutions to prove themselves worthy of male workers' acceptance. They were not allowed to present themselves in the role of an intimidated girl (Tanggaard, 2006). Yet, the findings indicate that the girls more or less consciously struggled against gender structures and prejudices. Gaining acceptance in the male-dominated workplace community sometimes meant a long journey for the girls, because it involved challenging established female stereotypes such as what women could do and also questioning dominant male ideals. Girls were often required to participating in male banter and humour, which also has 
been identified in other male-dominated vocational programmes (Kontio \& Evaldsson, 2015; Korp, 2011). Female students who met the requirements to participate in banter seemed to gain access to the repertoire of tools and guidance needed to learn the vocation. As they were often the only girl in the workplace, they had to find out for themselves what it was like to be a woman in this masculine workplace community (Paechter, 2003). It was up to them to negotiate the vocational identity (Wenger, 2010), and they therefore also developed their personal agency to make a difference and become a participant to count on in the workplace.

\section{Conclusions and Implications}

Forming a vocational identity as an industrial worker required the female students to meet challenges and fulfil different expectations due to their gender as part of their workplacebased learning. In order to do so, the girls mostly relied on their individual agency while interacting with others in the male-dominated workplace. As we have shown, the girls' strategies were part of and tied to a complex vocational identity formation process that involved contradictory requirements. By taking individual responsibility, the girls identified relevant information for becoming industrial workers and choosing to act like boys. They saw no problem with being a girl, but they struggled with implicit, diffuse and hidden gender structures and prejudices in the male-dominated workplace. Following these findings, the conclusion is that the girls seemed to form a 'gendered vocational identity'. This means that the vocational identity formation of the female students can be seen as a double process, in which vocational and gender identities were formed simultaneously and in parallel, interlaced within the male-dominated workplace. The girls strived for what they perceived to be an attractive vocational identity as industrial workers that were far removed from a typically feminine way of being. The male-dominated workplace community provided the girls with an alternative way of being a girl. Nevertheless, it could be hard for them to figure out what it meant to be a female industrial worker, but with the help of their strategies they actively negotiated the gendered vocational identities for changing their conditions as women in the workplace. In accordance with the girls' self-responsibility, the conditions they could change seemed to affect only themselves. The girls could not confront the general stereotype of women not being able to do industrial work - even though they behaved like men, leading to the reproduction of gender roles.

However, it is important to remember that these girls enrolled on the industrial programme were attracted by working in vocations in the industrial sector. Therefore, one of the implications of the findings of this study is that it is important for providers of vocational education to focus on learning conditions in local workplace environment in which students carry out their workplace-based learning. This requires engaging in a dialogue with industrial companies about how to create inclusive workplace environments that attract girls just as 
much as boys. One way to attract more girls into the male-dominated industrial sector can be to change attitudes to women working in manufacturing and process industries. Perhaps this is an overly extensive suggestion that requires measures to address gender segregation in the labour market in general, and in the male-dominated industrial sector in particular. A less modest suggestion is that girls on the industrial programme can be important female role models who can inspire by showing opportunities for girls who are considering working in a male-dominated industrial vocation.

\section{Acknowledgement}

The findings presented in this article is based on a study carried out in a larger research project focusing on vocational students' learning and identity formation on the industrial programme during their workplace-based learning. The project was financially supported by FORTE, the Swedish Research Council for Health, Working Life and Welfare.

\section{References}

Acker, J. (2006). Inequality regimes: Gender, class, and race in organizations. Gender \& Society, 20(4), 441-464. https://doi.org/10.1177\%2F0891243206289499

Armishaw, D. D. (2007). Vocational identity: It's about working at becoming. College Quarterly, 10(2), $1-13$.

Braun, V., \& Clarke, V. (2006). Using thematic analysis in psychology. Qualitative Research in Psychology, 3(2), 77-101. https://doi.org/10.1191/1478088706qp063oa

Colley, H. (2006). Learning to labour with feeling: Class, gender and emotion in childcare education and training. Contemporary Issues in Early Childhood, 7(1), 15-29. https://doi. org/10.2304\%2Fciec.2006.7.1.15

Ely, R. J. (1995). The power in demography: Women's social constructions of gender identity at work. Academy of Management journal, 38(3), 589-634. https://doi.org/10.5465/256740

Evans, K., Guile, D., Harris, J., \& Allan, H. (2010). Putting knowledge to work: A new approach. Nurse Education Today, 30(3), 245-251. https://doi.org/10.1016/j.nedt.2009.10.014

Ferm, L., Persson Thunqvist, D., Svensson, L., \& Gustavsson, M. (2018). Students' strategies for learning identities as industrial workers in a Swedish upper secondary school VET programme. Journal of Vocational Education \& Training, 70(1), 66-84. https://doi.org/10.1080/13636820.2017.139 4357

Fuller, A., \& Unwin, L. (2003). Learning as apprentices in the contemporary UK workplace: Creating and managing expansive and restrictive participation. Journal of Education and Work, 16(4), 407-426. https://doi.org/10.1080/1363908032000093012

Gustavsson, M., \& Fogelberg Eriksson, A. (2010). Gendered learning environments in managerial work. Studies in the Education of Adults, 42(2), 141-155. https://doi.org/10.1080/02660830.2010 .11661594 
Helms Jørgensen, C. (2013). The role and meaning of vocations in the transition from education to work. International Journal of Training Research, 11(2), 166-183. https://doi.org/10.5172/ ijtr.2013.11.2.166

Klotz, V. K., Billett, S., \& Winther, E. (2014). Promoting workforce excellence: Formation and relevance of vocational identity for vocational educational training. Empirical Research in Vocational Education and Training, 6(1), 1-20. https://doi.org/10.1186/s40461-014-0006-0

Kontio, J., \& Evaldsson, A. C. (2015). Last year we used to call it a man's hammer: (Un)doing masculinity in everyday use of working tools within vocational education. International Journal for Masculinity Studies, 10(1), 20-38. https://doi.org/10.1080/18902138.2015.1013343

Korp, H. (2011). What counts as being smart around here? The performance of smartness and masculinity in vocational upper secondary education. Education, Citizenship and Social Justice, 6(1), 21-37. https://doi.org/10.1177\%2F1746197910397909

Korvajärvi, P. I. (2002). Locating gender neutrality in formal and informal aspects of organizational cultures. Culture and Organization, 8(2), 101-115. https://doi.org/10.1080/14759550212838

Lahelma, E. (2011). Gender awareness in Finnish teacher education: An impossible mission? Education Inquiry, 2(2), 263-276. https://doi.org/10.3402/edui.v2i2.21979

Lappalainen, S., Lahelma, E., Pehkonen, L., \& Isopahkala-Bouret, U. (2012). Gender neutralities, dichotomies and hidden inequalities: Analysis of vocational teachers' reflections on gender in the profession. Vocations and Learning, 5(3), 297-311. https://doi.org/10.1007/s12186-012-9082-0

Lave, J., \& Wenger, E. (1991). Situated learning: Legitimate peripheral participation. Cambridge University Press.

Ledman, K., Nylund, M., Rönnlund, M., \& Rosvall, P. Å. (2020). Being and becoming a female student and worker in gendered processes of vocational education and training. Gender and Education, 1-17. https://doi.org/10.1080/09540253.2020.1815659

Paechter, C. (2003). Masculinities and femininities as communities of practice. Women's Studies International Forum 26(1), 69-77. https://doi.org/10.1016/S0277-5395(02)00356-4

Paechter, C. (2006a). Power, knowledge and embodiment in communities of sex/gender practice. Women's Studies International Forum 29(1), 13-26. https://doi.org/10.1016/j.wsif.2005.10.003

Paechter, C. (2006b). Masculine femininities/feminine masculinities: Power, identities and gender. Gender and Education, 18(3), 253-263. https://doi.org/10.1080/09540250600667785

Paola Sevilla, M., Sepúlveda, L., \& José Valdebenito, M. (2019). Gender differences production in secondary technical vocational education. Pensamiento Educativo, 56(1), 1-17.

Pleasant, E. (2019). Dirty work: Cultural iconography and working-class pride in industrial apprenticeships. The British Journal of Sociology, 70(5), 2116-2132. https://doi.org/10.1111/1468-4446.12703

Risberg, G. (2004). "I am solely a professional-neutral and genderless": On gender bias and gender awareness in the medical profession. (Doctoral dissertation).

Struthers, K., \& Strachan, G. (2019). Attracting women into male-dominated trades: Views of young women in Australia. International Journal for Research in Vocational Education and Training, 6(1), 1-19. https://doi.org/10.13152/IJRVET.6.1.1

Swedish National Agency for Education. (2020). Monitoring upper secondary school 2020 [Uppföljning av gymnasieskolan 2020]. https://www.skolverket.se/getFile?file=6585

Tanggaard, L. (2006). Situating gendered learning in the workplace. Journal of Workplace Learning, 18(4), 220-234. https://doi.org/10.1108/13665620610665827 
Wenger-Trayner, E., \& Wenger-Trayner, B. (2015). Learning in a landscape of practice. A framework. In E. Wenger-Trayner, M. Fenton-O'Creevy, S. Hutchinson, C. Kubiak, \& B. Wenger-Trayner (Eds.), Learning in a landscape of practice. Boundaries, identity, and knowledgeability in practicebased learning (pp. 13-29). Routledge.

Wenger, E. (1998). Communities of practice: Learning, meaning, and identity. Cambridge University Press.

Wenger, E. (2010). Conceptual tools for CoPs as social learning systems: Boundaries, identity, trajectories and participation. In C. Blackmore (Ed.), Social learning systems and communities of practice (pp. 125-143). Springer.

West, C., \& Zimmerman, D. H. (1987). Doing gender. Gender \& Society, 1(2), 125-151.

Wetherell, M., Stiven, H., \& Potter, J. (1987). Unequal egalitarianism: A preliminary study of discourses concerning gender and employment opportunities. British journal of social psychology, 26(1), 59-71. https://doi.org/10.1111/j.2044-8309.1987.tb00761.x

Åberg, M., \& Hedlin, M. (2015). Happy objects, happy men? Affect and materiality in vocational training. Gender and Education, 27(5), 523-538. https://doi.org/10.1080/09540253.2015.1069797

\section{Biographical Notes}

Lisa Ferm, PhD in sociology, works as lecturer at the Department of behavioural sciences and learning at Linköping University in Sweden. Her research focus on vocational identity formation amongst students in the upper secondary industrial program.

Maria Gustavsson is a professor in education at Linköping University in Sweden. She is also a research leader at the Helix Competence Centre, Linköping University. Her research includes vocational and professional learning, vocational education, and learning in work and working life. 